\title{
Immunohistochemical Investigation of Predictive Biomarkers for Mandibular Bone Invasion in Oral Squamous Cell Carcinoma
}

\author{
Takahiko Gibo $^{1} \cdot$ Shin-ichi Yamada ${ }^{1} \cdot$ Makiko Kawamoto $^{1} \cdot$ Takeshi Uehara $^{2} \cdot$ Hiroshi Kurita $^{1}$
}

Received: 20 April 2020 / Accepted: 19 May 2020 / Published online: 10 June 2020

(C) Arányi Lajos Foundation 2020

\begin{abstract}
The accurate preoperative determination of the extent of mandibular resection remains a challenge for the surgeons. The purpose of the present study was to immunohistochemically investigate predictive markers for histological bone invasion of oral squamous cell carcinoma (OSCC). The medical records of primary OSCC patients with mandibular bone contact in preoperative computed tomography scans between January 2003 and December 2017 were retrospectively reviewed and an immunohistochemical investigation was performed. Forty-five OSCC patients with mandibular bone contact radiographically were included in this study. Histopathologically, infiltrative bone invasion was observed in 19 patients (42.2\%) and compressive bone invasion in $15(33.3 \%)$. A correlation was noted between the histological pattern of bone invasion and mode of invasion (chi-squared test, $p<0.05$ ). At the tumor surface, a correlation was observed between the expression of IL- 6 and bone invasion (the Wilcoxon test, $p<0.05$ ), although the expression was so weak. At the bone contact area, the expression of both a-SMA and OPG correlated with infiltrative bone invasion (a-SMA; the Wilcoxon test, $p<0.05$, OPG; $\mathrm{p}<0.05$ ). These results suggest that predictive markers for aggressive (infiltrative) bone invasion in OSCC patients with a higher mode of invasion are the expression of a-SMA and OPG.
\end{abstract}

Keywords Oral squamous cell carcinoma $\cdot$ Mandible $\cdot$ Bone invasion $\cdot$ a-SMA $\cdot$ Predictive marker

\section{Introduction}

Oral squamous cell carcinoma (OSCC) is the most common malignant neoplasm among head and neck malignancies, and squamous cell carcinoma accounts for more than $90 \%$ of oral cancers [1]. Recent advances in treatment modalities for OSCC have improved the treatment outcomes of OSCC patients. However, standard radical therapy, including the wider resection of lesions often results in a decline in functions and quality of life (QOL) in OSCC patients [2].

As one of the anatomical characteristics of the oral cavity, the oral mucosa is close to the jaw bones, and OSCC sometimes easily and directly invades the maxillary and mandibular bones. The prevalence rate of mandibular invasion was

Shin-ichi Yamada

yshinshin@shinshu-u.ac.jp

1 Department of Dentistry and Oral Surgery, Shinshu University School of Medicine, 3-1-1, Asahi, Matsumoto 390-8621, Japan

2 Department of Laboratory Medicine, Shinshu University School of Medicine, 3-1-1, Asahi, Matsumoto 390-8621, Japan reported to be $42 \%$ in tongue OSCC, $48 \%$ in the retromolar region, and $62 \%$ in the oral floor [3]. Larger or more deeply invading OSCC was shown to more likely invade the mandiblar bone ${ }^{3}$. The bone invasion of OSCC is associated with a poor prognosis, upgrades the primary tumor stage, and causes facial deformity and/or oral dysfunction [4]. Although the prognostic impact of bone invasion remains controversial in OSCC patients, patients with bone invasion were found to have a significantly higher risk of recurrence than those without $[5,6]$. Wider resection of invaded jaw bone was required to achieve complete resection of tumor, while wider jaw bone resection may result in postoperative functional declines in mastication, speaking, and swallowing. Nescessary and minimum bone resection was required in the treatment of OSCC.

Clinically, mandibular bone invasion was diagnosed using imaging methods including panoramic radiography, CT, MRI, etc. The systematic review showed that current imaging methods give a moderate to high diagnostic accuracy for the detection of mandibular bone tissue invasion by SCC with sensitivity values of $94 \%$ (MRI), $91 \%$ (CBCT), $83 \%$ (CT) and $55 \%$ (panoramic radiography), and specificity values of $100 \%$ (CT, MRI, CBCT), 97\% (PET/CT) and 91.7\% (panoramic radiography) [7]. However, the accurate diagnosis of 
histological extent of bone invasion is sometimes difficult based on solely radiographic examinations [8]. The accurate preoperative determination of the extent of mandibular resection remains a challenge for the surgeons.

The tumor-associated stroma has been implicated in tumor progression including bone invasion [9]. OSCC was suggested to provide a suitable microenvironment for osteoclastogenesis by regulating the balance between RANKL and OPG [8]. In a recent study, cytokines, such as tumor necrosis factor- $\alpha(T N F-a)$ and parathyroid hormone-related protein (PTHrP), were shown to induce receptor activator of NF- $\mathrm{KB}$ ligand (RANKL) expression or osteoprotegerin (OPG) suppression in OSCC cells as well as osteoclastogenesis in cancer stromal cells [10]. However, the molecular mechanisms underlying the bone invasion of OSCC remain unclear. The molecular biomarkers which predict bone invasion may helpful in deciding the range of jaw resection. The biomarker may facilitate treatment decisions and improve the prognosis and QOL of OSCC patients.

Our final goal was to find a predictive biomarker for the bone invasion of OSCC. Therefore, in this paper, immunohistochemical study was conducted to find some possible biomarkers that have a significant association with histological bone invasion.

\section{Materials and Methods}

The protocol for the present study was approved by the Ethics Committee of the Shinshu University School of Medicine (No.4182). We published a research plan and guaranteed an opt-out opportunity on the homepage of our hospital.

The medical records of primary OSCC patients with mandibular bone contact in preoperative computed tomography (CT) scans, who were treated with surgery without preoperative adjuvant therapy at Shinshu University Hospital between January 2003 and December 2017, were retrospectively reviewed and an IHC investigation was performed to identify predictive biomarkers for bone invasion in OSCC patients. Forty-five patients preoperatively diagnosed with mandibular bone contact were enrolled in the present study. Data collection included age, sex, demographic information on tumors, histological differentiation, the TNM stage at diagnosis, mode of invasion, and treatment strategies. Tumor stages were classified according to the TNM classification of the International Union against Cancer [11]. The mode of invasion was defined according to Yamamoto et al. [12]. Histological differentiation and the mode of invasion were assessed using biopsy tissues obtained from the tumor surface.

In order to identify predictive markers for the bone invasion of OSCC, the IHC staining of surgical specimens was performed. Four-micrometer-thick serial sections were sliced from paraffin-embedded tissue blocks. Sections were deparaffinized in xylene, soaked in target retrieval solution buffer (Dako, Glostrup, Denmark), and placed in a microwave at $600 \mathrm{~W}$ for $25 \mathrm{~min}$ for antigen retrieval. Endogenous peroxidase was blocked by incubating sections with $0.3 \% \mathrm{H}_{2} \mathrm{O}_{2}$ in methanol for $30 \mathrm{~min}$. IHC staining was performed using the Envision system (Envision+, Dako, Carpentaria, CA). Candidate of bone invasion biomarker was listed in Table 1. The primary antibodies were anti-matrix metalloproteinase (MMP)-2 (NB200-193, Novus Biologicals, Centennial, CO, USA, 1:100) and MMP-9 (GTX100458, Gene Tex, Alton Pkwy Irvine, CA,USA, 1:250) antibodies for markers of the periosteum destruction, anti-E-cadherin $(610,181$, BD Biosciences, San Jose, CA, USA, 1:1000), N-cadherin (MA5-16324, Thermo Fisher, Scientific, Waltham, Massachusetts, USA, 1:125), and tumor growth factor- $\beta$ (TGF- $\beta$ ) (AF-246-NA, R\&D Systems, Minneapolis, MN, USA, 1:200) antibodies for markers of epithelialmesenchymal transition (EMT), anti a -smooth muscle actin (a-SMA) (A2547, Sigma Aldrich, St. Louis, Missouri, USA, 1:2000) and TGF- $\beta$ antibodies for markers of cancerassociated fibroblasts (CAF), anti-RANKL (ab9957, Abcam, Cambridge, CB, UK,1:500) and OPG (ab73400, Abcam, Cambridge, CB, UK, 1:400) antibodies for markers of bone metabolism, and anti-interleukin (IL)-6 (sc-28,343, Santa Cruz Biotechnology, Dallas, Texas, USA, 1:100) and monocyte chemotactic protein-1 (MCP-1) (ab9669, Abcam, Cambridge, CB, UK 1:100) antibodies. Sections were incubated with the primary antibody at $4{ }^{\circ} \mathrm{C}$ overnight. Reaction products were visualized by immersing the sections in diaminobenzidine (DAB) solution, and samples were counterstained with Meyer's hematoxylin and mounted. Negative controls were prepared by replacing the primary antibody with

Table 1 Candidate of bone invasion biomarker

Matrix metalloproteinase marker

MMP-2

MMP-9

EMT(epithelial mesenchymal transition) marker

E-cadherin

$\mathrm{N}$-cadherin

TGF- $\beta$

Cancer-associated fibroblast (CAF) marker

TGF- $\beta$

alfa-SMA

Bone metabolism marker

RANKL

OPG

Inflammatory marker

IL-6

MCP-1 
phosphate-buffered saline. All slides were evaluated by two independent authors (T.G and M.K) without knowledge of clinical outcomes. Each specimen was observed with an optical microscope at a magnification of $\times 100$ and at any three locations at the superficial and bone contact areas. Immunoreactivities were assessed with $\mathrm{H}$-scores, which were based on the staining intensity and immunoreactive cell percentage [13]. The final score was defined by multiplying quality and intensity scores.

The bone invasion was assessed histologically on the H-E stained sections. Presence of bone invasion was reported if erosive (compressive) or infiltative pattern of bone invasion was observed at tumor-bone contact area. The erosive (compressive) pattern involves a tumor mass that is cohesive and invades the connective tissue between a tumor and bone [3]. The infiltrative pattern is defined as the destruction of the invaded connective tissue and the infiltration of bone with tumor cell islands and fingers [3].To investigate the relationships between candidate biomarkers and bone invasion, the immunoactivitiy of each biomarker was sompared between the tumor with and without bone invasion. Immunoactivity was also compared between the erosive (compressive) and the infiltative pattern of bone invasion. Statistical analyses were conducted using JMP® 13.0 (SAS Institute Inc., Cary, NC, USA), and the Wilcoxon test and chi-squared test were employed to test the significance. All $p$ values less than 0.05 were considered to indicate significance.

\section{Results}

Forty-five OSCC patients suspected of having mandibular bone involvement were included in the study population. The characteristics of these patients were shown in Table 2. The median age at diagnosis was 67 years (range 50-91 years). The most common primary site was the lower gums (35 patients, $77.8 \%)$ followed by the oral floor $(8,17.8 \%)$, and tongue $(2,4.4 \%)$. According to TNM staging defined by the Union for International Cancer Control 7 th edition ${ }^{11}$, stage IVA was the most frequent in 27 patients $(60.0 \%)$, II in 7 $(15.6 \%)$, I in $6(13.3 \%)$, and III in $5(11.1 \%)$. Regarding the mode of invasion, grade 3 was the most common in 27 patients $(60.0 \%)$, grade $4 \mathrm{c}$ in $13(28.9 \%)$, and grade 2 in 5 (11.1\%). Histological bone invasion was detected in 34 patients $(75.6 \%)$, infiltrative bone invasion in $19(42.2 \%)$, and compressive bone invasion in $15(33.3 \%)$. While, other 11 patients had no histological bone invasion although the tumor contacted bone surface. Regarding the surgical strategy for OSCC, 24 patients $(53.3 \%)$ underwent marginal resection, $10(22.2 \%)$ segmental resection, and one (2.2\%) hemimandibulectomy.

The relationship between the type of bone invasion and either the histological tumor grade or mode of invasion was shown in Table 3. A correlation was observed between the type of bone invasion and mode of invasion ( $\mathrm{Y}-\mathrm{K}$ classification) (chi-squared test, $p<0.05$ ). The higher the

Table 2 Patients charecteristics

\begin{tabular}{lll}
\hline Sex & Male & 28 \\
Age & Female & 17 \\
Primary site & Median (range) & 67 (50-91) years old \\
& Lower gum & 35 \\
Stage & Oral floor & 8 \\
& Tongue & 2 \\
& I & 6 \\
Histologic grade & II & 7 \\
& III & 5 \\
Mode of invasion (YK classification) & IVa & 27 \\
& Well-differentiated & 28 \\
& Moderately-differentiated & 13 \\
Histological bone invasion & Poorly-differentiated & 4 \\
& Grade 2 & 5 \\
Resection of mandible & Grade 3 & 27 \\
& Grade 4c & 13 \\
& No bone invasion & 11 \\
& Compressive bone invasion & 15 \\
& Infiltrative bone invasion & 19 \\
& Marginal resection & 24 \\
& Segmental resection & 10 \\
& Hemimandiblectomy & 1 \\
\hline
\end{tabular}


Table 3 Correlation between type of bone invasion and either histological tumor grade (A) or mode of invasion (B)

\begin{tabular}{|c|c|c|c|}
\hline A. Histological grade & Well-diffetentiated & Moderately- differentiated & Poorly-differentiated \\
\hline No bone invasion (11) & 7 & 3 & 1 \\
\hline Compressive bone invasion (15) & 10 & 5 & 0 \\
\hline Infiltrative bone invasion (19) & 11 & 5 & 3 \\
\hline B. Mode of invasion (YK classification) ${ }^{\mathrm{a}}$ & Grade 2 & Grade 3 & Grade $4 \mathrm{c}$ \\
\hline No bone invasion (11) & 1 & 8 & 2 \\
\hline Compressive bone invasion (15) & 4 & 10 & 1 \\
\hline Infiltrative bone invasion (19) & 0 & 9 & 10 \\
\hline
\end{tabular}

${ }^{\mathrm{a}}$ Significance correlation between type of bone invasion and mode of invasion (chi square test, $\mathrm{p}<0.05$ )

mode of invasion, the more advanced the type of bone invasion. Infiltrative bone invasion was frequent in grade $4 \mathrm{c}$, but absent in grade 2.

The expression of MMP-2, MMP-9, E-cadherin, Ncadherin, a-SMA, TGF- $\beta$, RANKL, MCP-1, OPG, and IL-6 in histochemical staining was shown in Fig. 1. Figure 1a shows the area of tumor surface and $1 \mathrm{~B}$ shows the area of tumor-bone contact. MMP-2, MMp-9, N-cadherin, TGF- $\beta$, RANKL, OPG, and MCP-1 staining was detected in the cytoplasm of tumor cells (Fig. 1a, b, d, f, g, h, and i). E-cadherin expression were observed in the cell membrane (Fig. 1c). The expression of a-SMA was detected in fibroblasts and the stroma (Fig. 1e). IL-6 expression was detected in inflammatory cells and the stroma (Fig. 1j).
Fig. 1 Immunohistochemical investigation of potential bone invasion predictive markers. (a) at tumor surface area, (b) at tumorbone contacting area. $(\mathbf{a}-\mathbf{j})$ Immunohistochemical expression for (a) MMP-2, (b) MMP-9, (c) E-cadherin, (d) N-cadherin, (e) aSMA, (f) TGF- $\beta$, (g) RANKL, (h) MCP1, (i) OPG, and (j) IL-6. (a, b, d, f, g, h, and i) IHCpositive staining was detected in the cytoplasm of tumor cells. (c) E-cadherin expression were observed in the cell membrane. (e) The expression of a-SMA was detected in fibroblasts and the stroma. (j) IL-6 expression was detected in inflammatory cells and the stroma. $(\mathbf{a}-\mathbf{j})$

Magnification: $\times 100$

\section{A) Surface area}

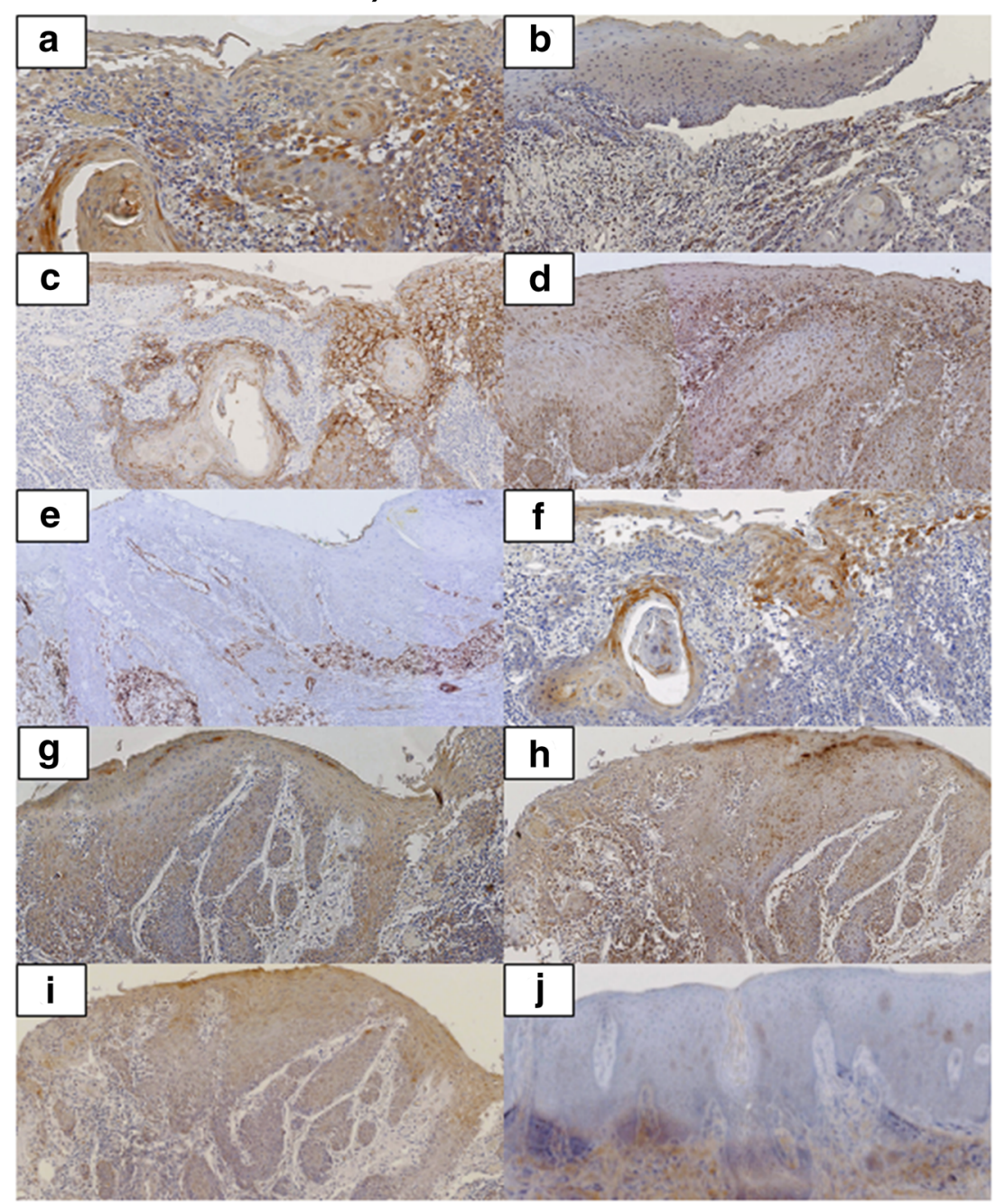




\section{B) Bone contacting area}

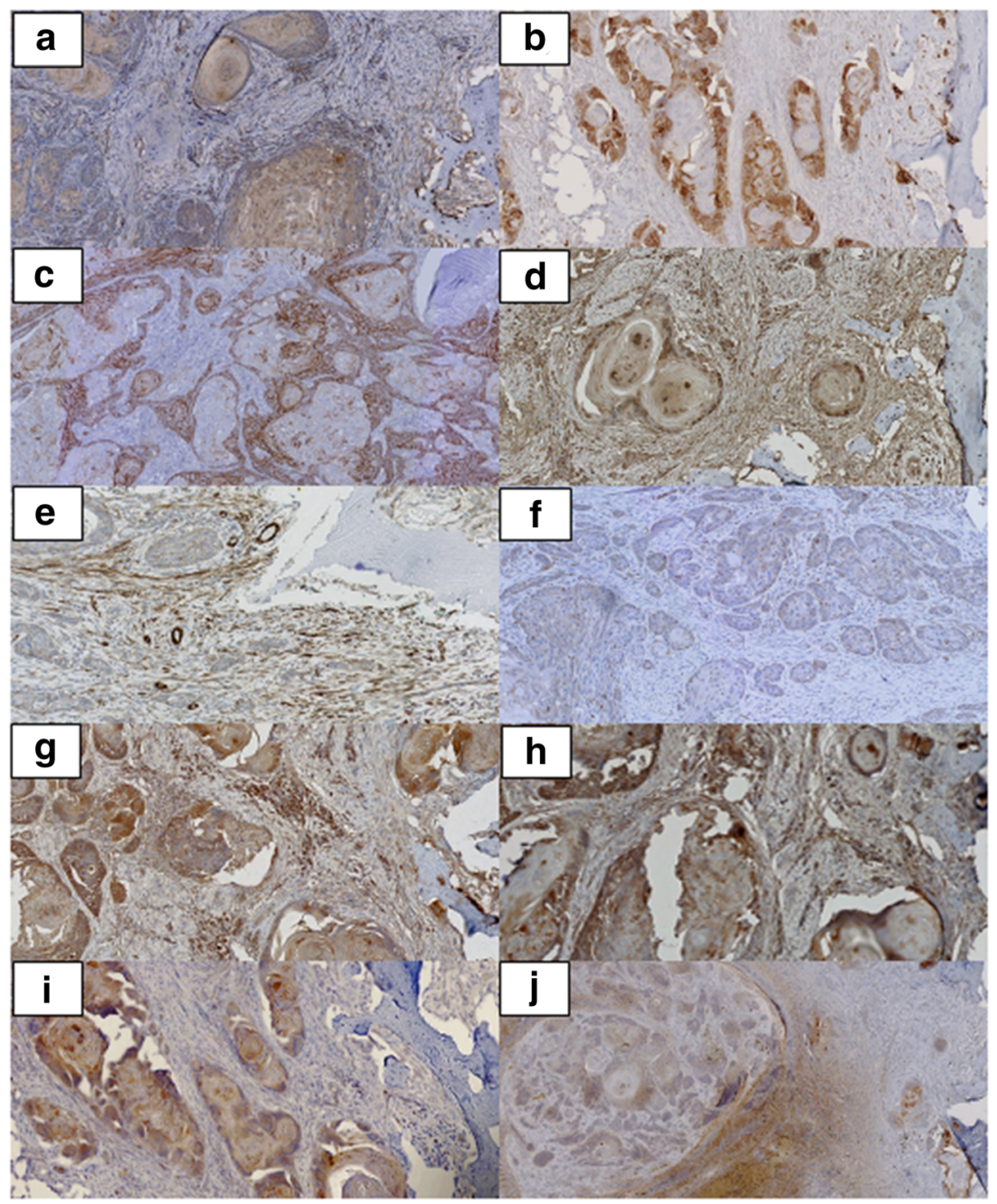

Fig. 1 (continued)

The result of comparison of IHC reactivity between tumors with and without bone invasion was shown in Table 4. At the tumor surface the immunoreactivity of IL-6 significantly differed between OSCC with and without bone invasion, although activity was very low (median H-score 8 vs 4 , the Wilcoxon test, $p<0.05$ ). At the bone contact area, a correlation was found between bone invasion and either E-cadherin or a-SMA. Immunoreactivity for E-cadherin and a-SMA was stronger in OSCC with than without bone invasion (Ecadherin; median $\mathrm{H}$-score 97.5 vs 71.5 , the Wilcoxon test, $p<0.05$ and a-SMA; 65 vs. 5.5 , the Wilcoxon test, $p<0.01$ ).

The immunoactivitiy of each biomarker was then compared among different type of bone invasions. Table 4 shows the difference in immunoactivity of each biomarker between OSCC with and without bone invasion. Significan differences were observed for IL-6 at tumor surface (median H-score 8 vs. 4, the Wilcoxon test, $p<0.05$ ), and for E- adherin (median Hscore 97.5 vs. 71.5 , the Wilcoxon test, $\mathrm{p}<0.05$ ) and for $\mathrm{a}-$
SMA (median H-score 65 vs. 5.5, the Wilcoxon test, $\mathrm{p}<0.05$ ) at bone contacting area. Table 5 shows differences in the immunoreactivity of each biomarker between OSCC with different pattern of bone invasion (infiltrative vs. compressive bone invasion). Significant differences were observed for a-SMA and OPG activities at bone contacting area. The expression of a-SMA was significantly higher in OSCC with infiltrative bone invasion than in that with compressive bone invasion (median H-score 79 vs. 48.5, the Wilcoxon test, $p<0.05)$. The expression of OPG was also significantly stronger in OSCC with infiltrative bone invasion than in compressive bone invasion (median; 40 vs 4.5 , Wilcoxon test, $\mathrm{p}<0.05$ ). While at the superficial area, although the expression of OPG was slightly stronger in OSCC with infiltrative bone invasion (median H-score, 14 vs 4 , the Wilcoxon test, $p=$ 0.058 ), there was no significant difference on immnoactivity in other biomarkers. 


\section{Discussion}

OSCC has been shown to invade the adjacent bone with a poor prognosis [14]. A previous study that investigated the patterns of mandibular invasion in 176 patients with lower gingival squamous cell carcinoma showed that mandibular invasion was absent in $35 \%$ of patients, while tumor invasion to the periosteum was observed in $34 \%$ [14]. The preoperative assessment of mandibular invasion is an important issue for the selection of treatment strategies. However, the accurate diagnosis of histological bone invasion is often difficult based on radiographic examinations [8].

In this study, possible predictive biomarkers for presence/ absence and type of bone invasion in OSCC were investigated using IHC. The results showed that potential predictive markers for bone invasion at the invasion front area may be the expression of E-cadherin, a-SMA, and OPG. In addition, A significant correlation was observed between the type of bone invasion and mode of invasion ( $\mathrm{Y}-\mathrm{K}$ classification). No infiltative bone invasion was observed in the tumor with low (Y-K grade 2) mode of invasion. The stronger expression of these molecules and the higher grade of tumor invasion may be predictive markers for aggressive (infiltrative) bone invasion.

The tumor-associated stroma was previously shown to play an important role in tumor progression in OSCC [9]. No direct contact has been detected between tumors and bone, and an abundant fibrous and variably desmoplastic stroma was found to intervene at the interface front between tumors and bone [15]. Although the intervention of the stoma was previously

Table 4 Difference in immunoactivity of each bio-markers between OSCC with and without bone invasion

\begin{tabular}{|c|c|c|c|c|c|c|}
\hline & \multicolumn{3}{|c|}{ Tumor surface } & \multicolumn{3}{|c|}{ Bone contacting area } \\
\hline & Median & IQR & Wilcoxon test & Median & IQR & Wilcoxon test \\
\hline \multicolumn{7}{|l|}{ MMP-2 } \\
\hline No bone invasion (11) & 32 & $5-37$ & NS & 42.5 & $32-59$ & NS \\
\hline With bone invasion (34) & 8 & $2.5-34.25$ & & 37 & $6-72.5$ & \\
\hline \multicolumn{7}{|l|}{ MMP-9 } \\
\hline No bone invasion (11) & 42.5 & $2-49$ & NS & 44 & $8-81$ & NS \\
\hline With bone invasion (34) & 6.75 & $4-40.5$ & & 45 & $15.5-85.625$ & \\
\hline \multicolumn{7}{|l|}{ E-cadherin } \\
\hline No bone invasion (11) & 59 & $53-67$ & NS & 71.5 & $58.5-89$ & $\mathrm{p}<0.05$ \\
\hline With bone invasion (34) & 54 & $31.75-79$ & & 97.5 & $72.625-121.375$ & \\
\hline \multicolumn{7}{|l|}{$\mathrm{N}$-cadherin } \\
\hline No bone invasion (11) & 4 & $2.5-10$ & NS & 4.5 & $2.5-14$ & NS \\
\hline With bone invasion (34) & 4.5 & $2.5-13.25$ & & 7 & $2.5-17.5$ & \\
\hline \multicolumn{7}{|l|}{ Alfa-SMA } \\
\hline No bone invasion (11) & 4.5 & $2.5-27$ & NS & 5.5 & $2.5-49$ & $\mathrm{p}<0.01$ \\
\hline With bone invasion (34) & 12.5 & $2.25-38.75$ & & 65 & $36.75-92.5$ & \\
\hline \multicolumn{7}{|l|}{ TGF- $\beta$} \\
\hline No bone invasion (11) & 23 & $7.5-51$ & NS & 46 & $36.5-64$ & NS \\
\hline With bone invasion (34) & 12 & $2.5-32.5$ & & 42.5 & $8.625-51.25$ & \\
\hline \multicolumn{7}{|l|}{ RANKL } \\
\hline No bone invasion (11) & 8 & $2.5-23.5$ & NS & 7.5 & $2.5-61$ & NS \\
\hline With bone invasion (34) & 5.5 & $2.5-14$ & & 8.5 & $2.5-51.375$ & \\
\hline \multicolumn{7}{|l|}{ MCP-1 } \\
\hline No bone invasion (11) & 6.5 & $2.5-26$ & NS & 6.5 & $2.5-58$ & NS \\
\hline With bone invasion (34) & 18.25 & $3.625-52.25$ & & 42 & $6.25-74.625$ & \\
\hline \multicolumn{7}{|l|}{ OPG } \\
\hline No bone invasion (11) & 23 & $4-57$ & NS & 38 & $2.5-74$ & NS \\
\hline With bone invasion (34) & 8.75 & $2.5-29$ & & 10.5 & $2.5-51.375$ & \\
\hline \multicolumn{7}{|l|}{ IL-6 } \\
\hline No bone invasion (11) & 8 & $4-24$ & $\mathrm{p}<0.05$ & 16 & $6.5-46$ & NS \\
\hline With bone invasion (34) & 4 & $2.375-10.375$ & & 6.75 & $3.25-32.625$ & \\
\hline
\end{tabular}


reported in bone invasive OSCC, these were mainly observational studies that did not perform molecular analyses to investigate the relationship between tumor-associated stroma and bone invasion $[16,17]$.

Although the tumor-associated stroma has been shown to include fibroblasts, endothelial cells, inflammatory cells, and an associated matrix, CAF with the expression of the myofibroblast marker a-SMA have been observed in several malignancies and are associated with a poor prognosis $[9,18-21]$. a-SMA-positive CAF have been detected in bone prior to tumor cell invation [15]. Consistent with previous findings [15], significantly higher numbers of a-SMA-positive fibroblasts were observed at the bone contact area in patients with bone invasion than in those without bone invasion. Regarding the invasion pattern, a discohesive invasion pattern correlated with an aggressive and destructive nature $[16,22]$. In the present study, a-SMA expression levels were significantly higher in patients with infiltrative bone invasion, with a focus on bone invasion patterns. These result suggested that a-SMA may be one of candidates which predict aggressive bone invasion.

E-cadherin is found in epithelial tissue and is a type of cell adhesion molecule, which play a key role in tumor invasion and metastasis. Quan et al. reported that loss of E-cadherin was observed in the OSCC with bone invasion [23]. While, in the results of this study, significant higher expression of E-cadherin was observed in the tumor with bone invasion than those without bone invasion. The result was inconsistent with them. In addition, our results did not show the correlation between the expression of Ecadherin and type of bone invasion (compressive vs. infiltative bone invasion). The role of E-cadherin in predicting bone invasion was unclear.

Table 5 Difference in immunoactivity of each biomarkers between OSCC with compressive and infiltrative bone invasion

\begin{tabular}{|c|c|c|c|c|c|c|}
\hline & \multicolumn{3}{|c|}{ Tumor surface } & \multicolumn{3}{|c|}{ Bone contacting area } \\
\hline & Median & IQR & Wilcoxon test & Median & IQR & Wilcoxon test \\
\hline \multicolumn{7}{|l|}{ MMP-2 } \\
\hline $\begin{array}{l}\text { Compressive bone invasion (15) } \\
\text { Infiltrative bone invasion (19) }\end{array}$ & $\begin{array}{l}20 \\
10\end{array}$ & $\begin{array}{l}5-60 \\
5-20\end{array}$ & NS & $\begin{array}{l}48 \\
29\end{array}$ & $\begin{array}{r}17.5-104 \\
14-64\end{array}$ & NS \\
\hline \multicolumn{7}{|l|}{ MMP-9 } \\
\hline $\begin{array}{l}\text { Compressive bone invasion (15) } \\
\text { Infiltrative bone invasion (19) }\end{array}$ & $\begin{array}{l}6.5 \\
7.5\end{array}$ & $\begin{array}{l}5-54 \\
2.5-28\end{array}$ & NS & $\begin{array}{l}47 \\
32\end{array}$ & $\begin{array}{l}9-120 \\
16-71\end{array}$ & NS \\
\hline \multicolumn{7}{|l|}{ E-cadherin } \\
\hline $\begin{array}{l}\text { Compressive bone invasion (15) } \\
\text { Infiltrative bone invasion (19) }\end{array}$ & $\begin{array}{l}74 \\
48\end{array}$ & $\begin{array}{l}33-104.5 \\
31-64\end{array}$ & NS & $\begin{array}{l}105 \\
76\end{array}$ & $\begin{array}{l}79-149 \\
69-109\end{array}$ & NS \\
\hline \multicolumn{7}{|l|}{$\mathrm{N}$-cadherin } \\
\hline $\begin{array}{l}\text { Compressive bone invasion (15) } \\
\text { Infiltrative bone invasion (19) }\end{array}$ & $\begin{array}{l}4 \\
5\end{array}$ & $\begin{array}{l}2.5-13 \\
2.5-27\end{array}$ & NS & $\begin{array}{l}7.5 \\
6.5\end{array}$ & $\begin{array}{l}2.5-16 \\
2.5-38\end{array}$ & NS \\
\hline \multicolumn{7}{|l|}{ Alfa-SMA } \\
\hline $\begin{array}{l}\text { Compressive bone invasion (15) } \\
\text { Infiltrative bone invasion (19) }\end{array}$ & $\begin{array}{l}9 \\
14\end{array}$ & $\begin{array}{l}1.5-46 \\
2.5-38\end{array}$ & NS & $\begin{array}{l}48.5 \\
79\end{array}$ & $\begin{array}{r}36-71 \\
52.5-126.5\end{array}$ & $\mathrm{p}<0.01$ \\
\hline \multicolumn{7}{|l|}{ TGF- $\beta$} \\
\hline $\begin{array}{l}\text { Compressive bone invasion (15) } \\
\text { Infiltrative bone invasion (19) }\end{array}$ & $\begin{array}{l}25.5 \\
6.5\end{array}$ & $\begin{array}{l}4-32 \\
2.5-34\end{array}$ & NS & $\begin{array}{l}44.5 \\
40.5\end{array}$ & $\begin{array}{r}7.5-51 \\
13-52.5\end{array}$ & NS \\
\hline \multicolumn{7}{|l|}{ RANKL } \\
\hline $\begin{array}{l}\text { Compressive bone invasion (15) } \\
\text { Infiltrative bone invasion (19) }\end{array}$ & $\begin{array}{l}6 \\
5\end{array}$ & $\begin{array}{l}2.5-13 \\
1.5-14\end{array}$ & NS & $\begin{array}{l}5 \\
46\end{array}$ & $\begin{array}{l}2.5-32 \\
2.5-53\end{array}$ & NS \\
\hline \multicolumn{7}{|l|}{ OPG } \\
\hline $\begin{array}{l}\text { Compressive bone invasion (15) } \\
\text { Infiltrative bone invasion (19) }\end{array}$ & $\begin{array}{l}4 \\
14\end{array}$ & $\begin{array}{l}2.5-26 \\
4-36\end{array}$ & $\mathrm{p}=0.058$ & $\begin{array}{l}4.5 \\
40\end{array}$ & $\begin{array}{r}2.5-46 \\
4-76\end{array}$ & $\mathrm{p}<0.05$ \\
\hline \multicolumn{7}{|l|}{ MCP-1 } \\
\hline $\begin{array}{l}\text { Compressive bone invasion (15) } \\
\text { Infiltrative bone invasion (19) }\end{array}$ & $\begin{array}{l}15.5 \\
21\end{array}$ & $\begin{array}{l}5-43 \\
2.5-61\end{array}$ & NS & $\begin{array}{l}27 \\
68\end{array}$ & $\begin{array}{r}5-48 \\
6.5-79\end{array}$ & NS \\
\hline \multicolumn{7}{|l|}{ IL-6 } \\
\hline $\begin{array}{l}\text { Compressive bone invasion (15) } \\
\text { Infiltrative bone invasion (19) }\end{array}$ & $\begin{array}{l}5 \\
3.5\end{array}$ & $\begin{array}{l}2.5-9.5 \\
0-13\end{array}$ & NS & $\begin{array}{l}5.5 \\
8\end{array}$ & $\begin{array}{r}4.5-54 \\
2.5-31.5\end{array}$ & NS \\
\hline
\end{tabular}


OSCC has been shown to provide a suitable microenvironment for osteoclastogenesis in order to regulate the balance between RNKL and OPG [10]. OPG has been reported to play an important role in the bone invasion of OSCC [24]. In the present study, the up-regulation of OPG expression was significantly greater in infiltrative bone invasion than in compressive bone invasion. The result was compatible with the report by Russmueller G, et al. [25]. However, the down-regulation of OPG expression in osteoblasts and stromal cells was observed in some other studies [24]. The effects of OPG expression in the bone invasion area remain controversial.

TGF- $\beta$ has been shown to induce EMT and is associated with bone invasion by enhancing the activity of osteoclasts in OSCC [26]. EMT drives tumor cell infiltration into adjacent tissue by the disassembly of tumor cells at the invasive front [27]. The gelatinases MMP-2 and -9 also contribute to EMT by enhancing tumor cell invasion and metastasis [28]. Furthermore, the expression of MMP-2 and -9 have been shown to correlate with EMT triggered by TGF- $\beta$ [29]. In the present study, no correlations were observed between bone invasion and EMT markers, such as TGF- $\beta, \mathrm{N}$-cadherin, and MMPs.

At the tumor surface, where preoperative biopsy was usually carried out, only IL-6 showed the significant relathionship with presence or absence of bone invasion. However, we felt fear that the expression level of IL- 6 was so weak even in the bone invading tumor that it could not become a reliable biomarker for bone invasion. In this study, significant correlations between the expression of biomarker and bone invasion was observed at the tumor-bone contacting area. In most of clinical situation, preoperative biopsy at tumor-bone contacting area was difficult. These facts suggested the situation that the biomarkers might be not available for the surgeons preoperatively. We are planning further studies which find biomarkers related with a-SMA and OPG that can detected at the tumor surface (preoperative biopsy).

The strength of the present study is that it investigated predictive markers for bone invasion in OSCC patients, and the results obtained identified the mode of invasion and expression of a-SMA and OPG expression as potential predictive marker of aggressive bone invasion, although the direction of regulation of OPG remained controversial. The results suggest the possibility that OSCC patients with a mode of invasion less than grade 2 might not need to undergo invasive mandibulectomy. Among OSCC patients with higher grade mode of invasion, patients with strong a-SMA expression might be benefitted with aggressive mandibulectomy. However, there are some limitations in the present study, such as its retrospective nature based on a relatively small number of cases at a single institute. Therefore, there was insufficient power to statistically investigate predictive markers for bone invasion. Further studies based on a large number of cases with multicenter studies are warranted.
In conclusion, the expression of a-SMA and OPG in the bone contact area correlated with infiltrative bone invasion. aSMA and OPG may be a predictive biomarkers for aggressive bone invasion in OSCC. In most of clinical situation, preoperative biopsy at tumor-bone contacting area was difficult and, thus, the biomarkers might be not available for the surgeons preoperatively. Further studies which track down more effective biomarkers will be required.

Data Availability The datasets during and/or analysed during the current study available from the corresponding author on reasonable request.

\section{Compliance with Ethical Standards}

\section{Conflicts of Interest/Competing Interests None}

Ethical Approval This study was approved by the Committee on Medical Research of Shinshu University (No4182).

Consent to Participate Patient consent was not required in this study.

Consent for Publication Not applicable.

Code Availability Not applicable.

\section{References}

1. Johnson NW, Jayasekara P, Amarasinghe AA (2011) Squamous cell carcinoma and precursor lesions of the oral cavity: epidemiology and aetiology. Periodontol 57:19-37

2. Yamada SI, Kurita H, Tomioka T, Ohta R, Yoshimura N, Nishimaki F, Koyama Y, Kondo E, Kamata T (2017) Healthy life expectancy of oral squamous cell carcinoma patients aged 75years and older. Oral Oncol 64:22-26

3. Brown JS, Lowe D, Kalavrezos N, D'Souza J, Magennis P, Woolgar J (2002) Patterns of invasion and routes of tumor entry into the mandible by oral squamous cell carcinoma. Head Neck 24: 370-383

4. Chen YL, Kuo SW, Fang KH, Hao SP (2011) Prognostic impact of marginal mandibulectomy in the presence of superficial bone invasion and the nononcologic outcome. Head Neck 33:708-713

5. Vaassen LAA, Speel EM, Kessler PAWH (2017) Bone invasion by oral squamous cell carcinoma: molecular alterations leading to osteoclastogenesis - a review of literature. J Craniomaxillofac Surg 45:1464-1471

6. Du W, Fang Q, Wu Y, Wu J, Zhang X (2019) Oncologic outcome of marginal mandibulectomy in squamous cell carcinoma of the lower gingiva. BMC Cancer 19:775. https://doi.org/10.1186/ s12885-019-5999-0

7. Uribe S, Rojas LA, Rosas CF (2013) Accuracy of imaging methods for detection of bone tissue invasion in patients with oral squamous cell carcinoma. Dentomaxillofac Radiol 42:20120346

8. Totsuka Y, Usui Y, Tei K, Fukuda H, Shindo M, Lizuka T, Amemiya A (1991) Mandibular involvement by squamous cell carcinoma of the lower alveolus: analysis and comparative study of histologic and radiologic features. Head Neck 13:40-50

9. De Wever O, Demetter P, Mareel M, Bracke M (2008) Stromal myofibroblasts are drivers of invasive cancer growth. Int J Cancer 123:2229-2238 
10. Michalek J, Brychtova S, Pink R, Dvorak Z (2019) Prognostic and predictive markers for perineural and bone invasion of oral squamous cell carcinoma. Biomed Pap Med Fac Univ Palacky Olomouc Czech Repub 163:302-308. https://doi.org/10.5507/bp.2019.032

11. Sobin LH, Gospodarowicz MK, Wittekind C (eds) (2009) TNM classification of malignant tumours, 7th edn. Wiley-Blackwell, Chichester

12. Yamamoto E, Miyakawa A, Kohama G (1984) Mode of invasion and lymph node metastasis in squamous cell carcinoma of the oral cavity. Head Neck Surg 6:938-947

13. Hirsch FR, Varella-Garcia M, Bunn PA Jr, Di Maria MV, Veve R, Bremmes RM, Barón AE, Zeng C, Franklin WA (2003) Epidermal growth factor receptor in non-small-cell lung carcinomas: correlation between gene copy number and protein expression and impact on prognosis. J Clin Oncol 21:3798-37807

14. Nomura T, Shibahara T, Cui NH, Noma H (2005) Patterns of mandibular invasion by gingival squamous cell carcinoma. J Oral Maxillofac Surg 63:1489-1493

15. Elmusrati AA, Pilborough AE, Khurram SA, Lambert DW (2017) Cancer-associated fibroblasts promote bone invasion in oral squamous cell carcinoma. Br J Cancer 117:867-875

16. Ebrahimi A, Murali R, Gao K, Elliott MS, Clark JR (2011) The prognostic and staging implications of bone invasion in oral squamous cell carcinoma. Cancer 117:4460-4467

17. Fried D, Mullins B, Weissler M, Shores C, Zanation A, Hackman T, Shockley W, Hayes N, Chera BS (2014) Prognostic significance of bone invasion for oral cavity squamous cell carcinoma considered T1/T2 by American joint committee on cancer size criteria. Head Neck 36:776-781

18. Radisky DC, Kenny PA, Bissell MJ (2007) Fibrosis and cancer: do myofibroblasts come also from epithelial cells via EMT? J Cell Biochem 101:830-839

19. Saadi A, Shannon NB, Lao-Sirieix P, O'Donovan M, Walker E, Clemons NJ, Hardwick JS, Zhang C, Das M, Save V, Novelli M, Balkwill F, Fitzgerald RC (2010) Stromal genes discriminate preinvasive from invasive disease, predict outcome, and highlight inflammatory pathways in digestive cancers. Proc Natl Acad Sci U S A 107:2177-2182

20. Vered M, Dayan D, Yahalom R, Dobriyan A, Barshack I, Bello IO, Kantola S, Salo T (2010) Cancer-associated fibroblasts and epithelial-mesenchymal transition in metastatic oral tongue squamous cell carcinoma. Int J Cancer 127:1356-1362
21. Marsh D, Suchak K, Moutasim KA, Vallath S, Hopper C, Jerjes W, Upile T, Kalavrezos N, Violette SM, Weinreb PH, Chester KA, Chana JS, Marshall JF, Hart IR, Hackshaw AK, Piper K, Thomas GJ (2011) Stromal features are predictive of disease mortality in oral cancer patients. J Pathol 223:470-481

22. Ishikuro M, Sakamoto K, Kayamori K, Akashi T, Kanda H, Izumo T, Yamaguchi A (2008) Significance of the fibrous stroma in bone invasion by human gingival squamous cell carcinomas. Bone 43 : $621-627$

23. Quan J, Du Q, Hou Y, Wang Z, Zhang J (2017) Utilization of Ecadherin by monocytes from tumour cells plays key roles in the progression of bone invasion by oral squamous cell carcinoma. Oncol Rep 38:850-858. https://doi.org/10.3892/or.2017.5749

24. Tada T, Jimi E, Okamoto M, Ozeki S, Okabe K (2005) Oral squamous cell carcinoma cells induce osteoclast differentiation by suppression of osteoprotegerin expression in osteoblasts. Int J Cancer 116:253-262

25. Russmueller G, Moser D, Würger T, Wrba F, Christopoulos P, Kostakis G, Seemann R, Stadler V, Wimmer G, Kornek G, Psyrri A, Filipits M, Perisanidis C (2015) Upregulation of osteoprotegerin expression correlates with bone invasion and predicts poor clinical outcome in oral cancer. Oral Oncol 51:247-253

26. Quan J, Elhousiny M, Johnson NW, Gao J (2013) Transforming growth factor- $\beta 1$ treatment of oral cancer induces epithelialmesenchymal transition and promotes bone invasion via enhanced activity of osteoclasts. Clin Exp Metastasis 30:659-670

27. Ozaki-Honda Y, Seki S, Fujiwara M, Matsuura M, Fujita S, Ikeda H, Umeda M, Ayuse T, Ikeda T (2017) Prognostic prediction of Oral squamous cell carcinoma by E-cadherin and N-cadherin expression in overall cells in tumor nests or tumor cells at the invasive front. Cancer Microenviron 10:87-94

28. Kessenbrock K, Plaks V, Werb Z (2010) Matrix metalloproteinases: regulators of the tumor microenvironment. Cell 141:52-67

29. Qiao B, Johnson NW, Gao J (2010) Epithelial-mesenchymal transition in oral squamous cell carcinoma triggered by transforming growth factor-beta1 is snail family-dependent and correlates with matrix metalloproteinase-2 and -9 expressions. Int J Oncol 37:663668

Publisher's Note Springer Nature remains neutral with regard to jurisdictional claims in published maps and institutional affiliations. 